\title{
(5) Benign Gastric Lesions Conf used with the Early Cancer of the Stomach
}

\author{
Hisayuki Masuda \\ Medical Department (Director: Prof. S. YAMAGATA) \\ Tohoku University School of Medicine, Sendai
}

In one hundred and eighty-five patients with the early cancer of the stomach experienced in the Medical Department of Professor Dr. S. Yamagata of the Tohoku University Medical School in the past 9 years, 161 cases were diagnosed as such by endoscopic method. Namely, the diagnostic ability of the endoscopic method is $87.0 \%$. The rate of the ability to establish the type of the early cancer was found to be as followings: type I $58.4 \%$, type Ila $63.6 \%$, type IIc $91.7 \%$, type III $83.3 \%$. The rate was lower in type I and Ila and averaged, in these standard types, as $89.6 \%$. The intra-mucosal cancer was $69.6 \%$ and lower than the rate found in the cancer with the submucosal infiltration which was $93.1 \%$ and shows the difficulty of the diagnosis in this group. The diagnostic ability in other mixed types such as IIc +Ila, IIc+III etc. was higher than $90 \%$ with the average of $96.4 \%$ and with no demonstrable difference between the cancers with the submucosal and intramucosal infiltrations. The diagnostic ability rates of X-ray examination and cytological method were found to be each $88.8 \%$ and $90.4 \%$. About $10 \%$ of the cases were erroneously diagnosed.

When all these methods were combined, the diagnostic ability in 178 patients was found to be $98.3 \%$, demonstrating the importance of the combined efforts. The diagnosis at the time of the surgical intervention in 166 cases with the endoscopically diagnosed early cancer of the stomach was found to be divided into 102 cases with the early cancer, 37 case with the advanced cancer and others. Therefore, in true meaning, the correct diagnosis can be achieved by endoscopic examination in $61.4 \%$ and if advanced cancer cases were included the rate is $83.7 \%$. In 296 cases with the endoscopically diagnosed advanced cancer of the stomach, the surgical diagnosis confirmed the diagnosis in 263 cases, namely 88.8\%. Furthermore, if additional 25 cases in whom the surgical diagnosis was the early cancer of the stomach were to be added, then the total diagnostic ability rate increases up to $97.2 \%$.

In 166 cases with the endoscopically diagnosed early cancer of the stomach, 26 cases, namely 15.7\%, had benign stomach diseases. These include gastric ulcer in 19 cases, namely in $73.0 \%$, benign erosion in one case, namely in 20 cases, $76.9 \%$ had benign ulcerative diseases. Diseases characterized by the elevated lesion were found in 4 cases, $15.4 \%$, where the diagnosis was either polyp or benign atypia. In 2 cases, $7.7 \%$, the lesion showed both convex and concave characteristics. 
In these 19 cases with the gastric ulcer, 11 patients had solitary lesion, and 9 cases were diagnosed at type III by the endoscopic method showing the difficulty of the diagnosis of type III early cancer. Two cases were diagnosed as III plus IIc, This is due to the fact that IIc characteristics is added to the III the diagnosis of the cancer becomes easier. Multiple ulcers were found in 2 cases. Because of the fact that in multiple ulcers, if lesions are locating very close to each other, surrounding area shows nodular elevation which can be interpreted, although erroneously, as showing the characteristics of III plus Ila or IIc plus IIa. The linear ulcer was found in 3 cases. Each of them was diagnosed as IIc +III, III+IIc and III+IIa. Additional 3 cases had cicatrical healing and were diagnosed either as IIc or III+IIc. About half of these 19 ulcer patients were diagnosed as the cancer by X-ray examination, however, cytological diagnosis was positive in only one patient demonstrating the importance of the cytological contribution in making the diagnosis.

The one patient with the benign erosion was diagnosed as IIc and both X-ray

Table 1. Benign Gastric Lesions as the Early Cancer of the Stomach by Endoscopic Examination

\begin{tabular}{|c|c|c|c|c|c|}
\hline \multicolumn{2}{|c|}{$\begin{array}{l}\text { Histological DX } \\
\text { Surgical Specimen }\end{array}$} & Type & X-Ray DX & $\begin{array}{l}\text { Cytological } \\
\text { Test }\end{array}$ & Total \\
\hline \multirow{5}{*}{ Gastric Ulcer } & Single & $\begin{array}{l}\text { III } \\
\text { III } \\
\text { III + IIC } \\
\text { III + IIC }\end{array}$ & $\begin{array}{l}\text { Cancer } \\
\text { Ulcer } \\
\text { Ulcer } \\
\text { Ulcer }\end{array}$ & $\begin{array}{l}- \\
- \\
- \\
+\end{array}$ & $\begin{array}{l}4 \\
5 \\
1 \\
1(11)\end{array}$ \\
\hline & Multiple & $\begin{array}{l}I I I+I I a \\
I I c+I I a\end{array}$ & $\begin{array}{l}\text { Cancer } \\
\text { Ulcer+ Cancer }\end{array}$ & - & $\begin{array}{l}1 \\
1(2)\end{array}$ \\
\hline & Linear & $\begin{array}{l}\text { IIc }+ \text { III } \\
\text { III }+ \text { IIc } \\
I I I+I I a\end{array}$ & $\begin{array}{l}\text { Cancer } \\
\text { Ulcer } \\
\text { Ulcer }\end{array}$ & $\begin{array}{l}- \\
- \\
-\end{array}$ & $\begin{array}{l}1 \\
1 \\
1(3)\end{array}$ \\
\hline & Scar & $\begin{array}{l}\text { IIc } \\
\text { III }+ \text { IIc }\end{array}$ & $\begin{array}{l}\text { Cancer } \\
\text { Ulcer }\end{array}$ & - & $\begin{array}{l}2 \\
1(3)\end{array}$ \\
\hline & Total & & & & 19 \\
\hline \multicolumn{2}{|c|}{ Localized Benign Gastric Erosion } & IIc & Cancer & + & 1 \\
\hline \multicolumn{2}{|l|}{ Polyp } & $\mathrm{IIa}$ & Cancer & + & 1 \\
\hline \multicolumn{2}{|l|}{ Benign Atypia } & $\mathrm{IIa}$ & Cancer & + & 3 \\
\hline \multicolumn{2}{|l|}{ Reticuloma } & $\mathrm{IIa}+\mathrm{IIC}$ & Cancer & - & 1 \\
\hline \multicolumn{2}{|c|}{ Heterotopia of the Gastric Gland } & $\mathrm{IIa}+\mathrm{IIc}$ & Cancer & - & 1 \\
\hline \multicolumn{2}{|l|}{ Total } & & & & 7 \\
\hline \multicolumn{2}{|l|}{ Total } & \multicolumn{4}{|r|}{26} \\
\hline
\end{tabular}


and cytological diagnosis were cancer. The resected stomach demonstrated exactly same characteristics of type IIc early cancer of the stomach.

The 4 cases with benign elevated lesions who were mis-diagnosed as having the early cancer of the stomach include one case with polyp and 3 cases with benign atypia. All of these cases had histologically high graded atypia. One case with reticuloma and another case with the heterotopic gastric gland had negative cytological findings. Attention should be payed on this fact.

To summarize, 26 cases with benign gastric lesions were diagnosed as the early cancer of the stomach. About $3 / 4$ of them were cases with gastric ulcer. Cytological examination is important and repeated examination where all X-ray, endoscopic and cytological methods are included, will minimize the incidence of this kind. 